\title{
UWB Band-Notched Monopole Antenna with Defected Ground Structure
}

\author{
V.N.Koteswara rao, Devana, N. Vyuha, P. Naga sai, K. Sahitya, K. Divya and K. \\ Maheswarareddy \\ ${ }^{1}$ Assistant Professor, SACET, Chirala, AP, India \\ ${ }^{2}$ Students of Dept. of ECE, SACET, Chirala, AP, India \\ ${ }^{1}$ dvnkrao@gmail.com
}

\begin{abstract}
A compact planar monopole antenna with standard band-notched characteristic suitable for ultra wideband (UWB) applications is presented. This microstrip-fed antenna, consisting of an inverted $U$-shaped slot on the radiating patch with defected ground structure. The designed antenna has a small size of $12 \times 18 \times 1.6 \mathrm{~mm}^{3}$ and operates over the frequency band between 3.7 and $10.4 \mathrm{GHz}$ for VSWR $<2$, while showing the band rejection performance in the frequency band of 5.1 to $5.9 \mathrm{GHz}$ (WLAN) and is suitable for applications of communication systems, wireless communications, various kinds of antenna test ranges, and high resolution microwave imaging systems. The proposed UWB antenna is simulated by using the CST Microwave studio.
\end{abstract}

Keywords: Ultra Wideband (UWB) Antenna, Monopole Antenna, Band-Notched Characteristics

\section{Introduction}

Ultra wideband (UWB) antennas have drawn great attention in recent years for enabling high data rates, increased communication security, low power consumption and simple hardware configuration in practical applications. The United States, Federal Communication Commission (FCC) define frequency band from 3.1 to $10.6 \mathrm{GHz}$ for unlicensed wireless communication including VSWR less than 2.0, omnidirectional radiation patterns, minimum distortions in the received waveforms, etc [1]. The performance of the UWB antennas in both time and frequency domain are of equally importance which makes the UWB antenna design a challenging and interesting field of research [2-4]. The ultra-wideband (UWB) radio system has been getting increasingly popular from the academic and industry fields. As the key component of the UWB wireless communication system, the UWB antenna has drawn increasing attention [5].

Monopole antennas with microstrip feed line are widely used in designing UWB antenna because of low profile, low cost, light weight, easy fabrication, designing in desirable shape and integration with printed circuit boards. They also have UWB impedance matching (more than 100\%). The printed monopole antenna showed advantages due to its compact size, simple structure, wideband realizable characteristic, omnidirectional radiation patterns, high radiation efficiency and low cost. The patch of this type of reported antennas has different shapes such as rectangular, disc, triangle and elliptical forms [6-7]. There are many techniques that consist of changes on patch, feed line, and ground structure which is introduced as the most important of all to enhance the bandwidth and access to UWB bandwidth. Nowadays slot antennas are a typical kind of UWB antenna [8].

The design of the UWB antenna also comprises some of the challenges due to the interference with existing narrowband wireless communication systems within the UWB frequency range, for example, the wireless local area network (WLAN) for IEEE 802.11a 
operating at 5.15-5.35 and 5.725-5.825GHz. To avoid the interferences, it is necessary to filter out the overlapping frequency bands. Therefore, UWB antennas with band-notched characteristics for filtering the potential interference are desirable [9-10].

In the presented work, UWB monopole antenna with the band-notched characteristics is designed. Here, the notched band is from 5.1-5.9 GHZ which is known to be wireless local area network (WLAN) and the designed antenna occupies the UWB frequency from 3.7 to 10.4 GHZ.

\section{Antenna Design Structure}

The geometry and configuration of the final optimized UWB monopole antenna with microstrip line feeding is shown in the Figure 1. The designed antenna features a compact size of $12 \times 18 \mathrm{~mm}^{2}$ and it is printed on conventional FR4 substrate with thickness of 1.6 $\mathrm{mm}$ and relative permittivity $\left(\varepsilon_{r}\right)$ of 4.3 . The basic structure of the proposed UWB antenna consists of a square radiating patch, a feed-line and a ground plane. The dimensions of the proposed UWB antenna are as shown in the Table 1.

Table 1. Dimensions of the Proposed UWB Antenna

\begin{tabular}{|l|l|l|l|l|l|l|l|l|l|}
\hline Param. & $\mathrm{mm}$ & Param. & $\mathrm{mm}$ & Param. & $\mathrm{mm}$ & Param. & $\mathrm{mm}$ & Param. & $\mathrm{mm}$ \\
\hline $\mathrm{W}_{\text {sub }}$ & 12 & $\mathrm{~L}_{\text {sub }}$ & 18 & $\mathrm{~h}_{\text {sub }}$ & 1.6 & $\mathrm{~W}_{\mathrm{f}}$ & 2 & $\mathrm{~L}_{\mathrm{f}}$ & 7 \\
\hline $\mathrm{W}$ & 10 & $\mathrm{~L}$ & 10 & $\mathrm{~W}_{1}$ & 3.25 & $\mathrm{~L}_{1}$ & 3.5 & $\mathrm{~W}_{2}$ & 1 \\
\hline $\mathrm{L}_{2}$ & 2 & $\mathrm{~W}_{3}$ & 4.5 & $\mathrm{~L}_{3}$ & 0.75 & $\mathrm{~W}_{4}$ & 1.5 & $\mathrm{~L}_{4}$ & 0.5 \\
\hline $\mathrm{W}_{5}$ & 2.5 & $\mathrm{~L}_{5}$ & 2.75 & $\mathrm{~W}_{6}$ & 0.5 & $\mathrm{~L}_{\mathrm{gnd}}$ & 3.5 & $\mathrm{D}$ & 1 \\
\hline $\mathrm{SL}_{1}$ & 6.5 & $\mathrm{SL}_{2}$ & 5.3 & $\mathrm{SL}_{\mathrm{W}}$ & 0.3 & - & - & - & - \\
\hline
\end{tabular}

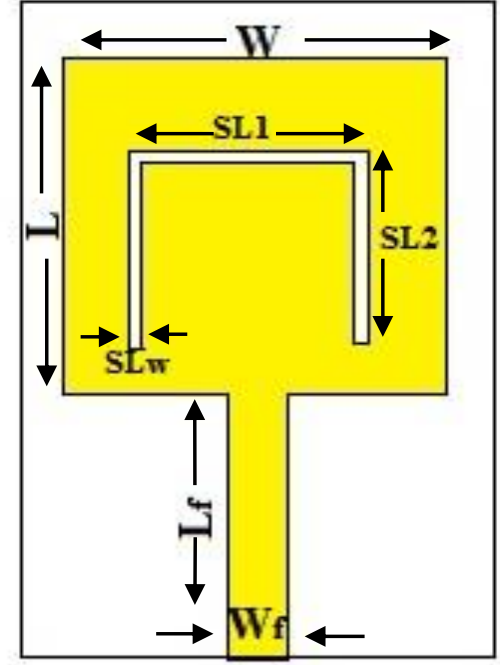

Front view

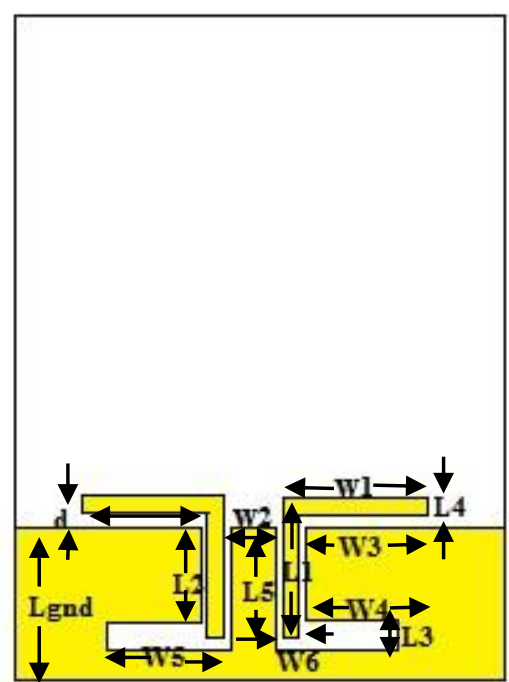

Back view

Figure 1. Geometry of the Proposed UWB Antenna

As shown in Figure 1, the ground plane is a defected ground Structure (DGS) because in the design of the ground plane, L-shaped slits along with a pair of inverted L-shaped parasitic structures are embedded. The material taken for the ground plane and for the radiating patch is copper (annealed). An inverted U-shaped slot is placed on the radiating rectangular patch.

There is a lot of flexibility in choosing the width of the radiating patch. This parameter mostly affects the antenna bandwidth. As $W$ decreases, so does the antenna bandwidth, and vice versa. The length $L$ of the radiating patch depends on a number of parameters 
such as the radiating patch width, thickness and dielectric constant of the substrate on which the antenna is fabricated.

\section{Simulation Results}

The proposed UWB antenna is simulated with CST Microwave studio. The simulated return loss of the UWB antenna with the band notch is shown in Figure 2. As mentioned earlier, to reduce the interference from WLAN systems, the band notch function is desirable. From Figure 2, the simulation results of the proposed UWB antenna has a wide bandwidth ranging from $3.7 \mathrm{GHz}$ to $10.4 \mathrm{GHz}$ with a band notch from $5.1 \mathrm{GHz}$ to 5.9 $\mathrm{GHz}$. This notch band is created by etching an inverted U-shaped slot in the radiating patch. The VSWR plot is shown in Figure 3. The designed antenna shows good characteristics for UWB, satisfying good VSWR less than 2 in the frequency band 3.7 to $10.4 \mathrm{GHZ}$.

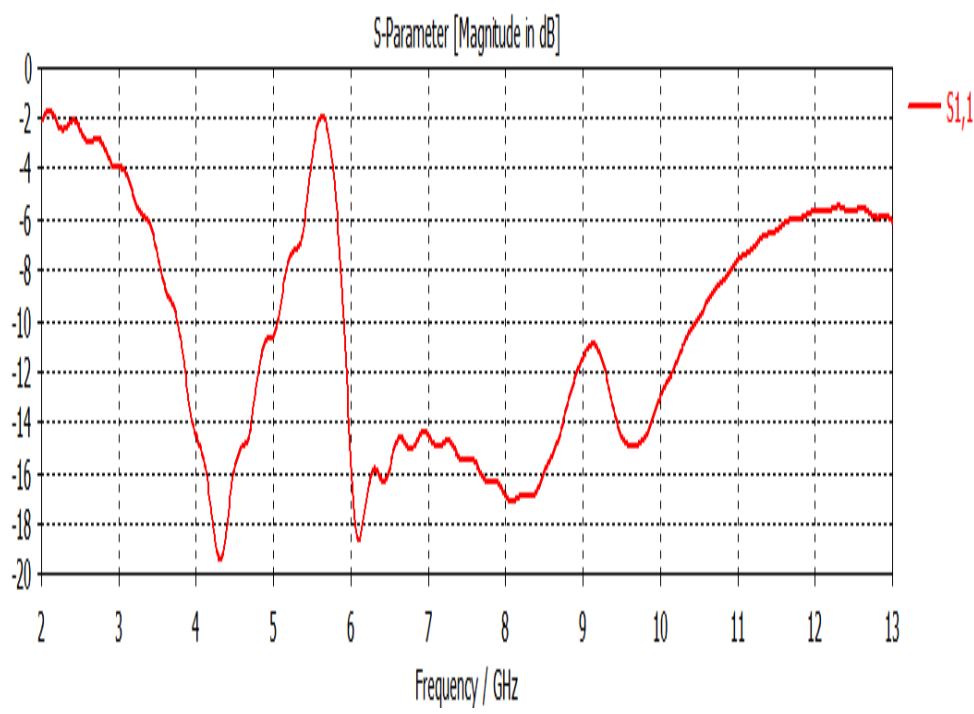

Figure 2. Return Loss of the Proposed UWB Antenna with Notching Characteristics

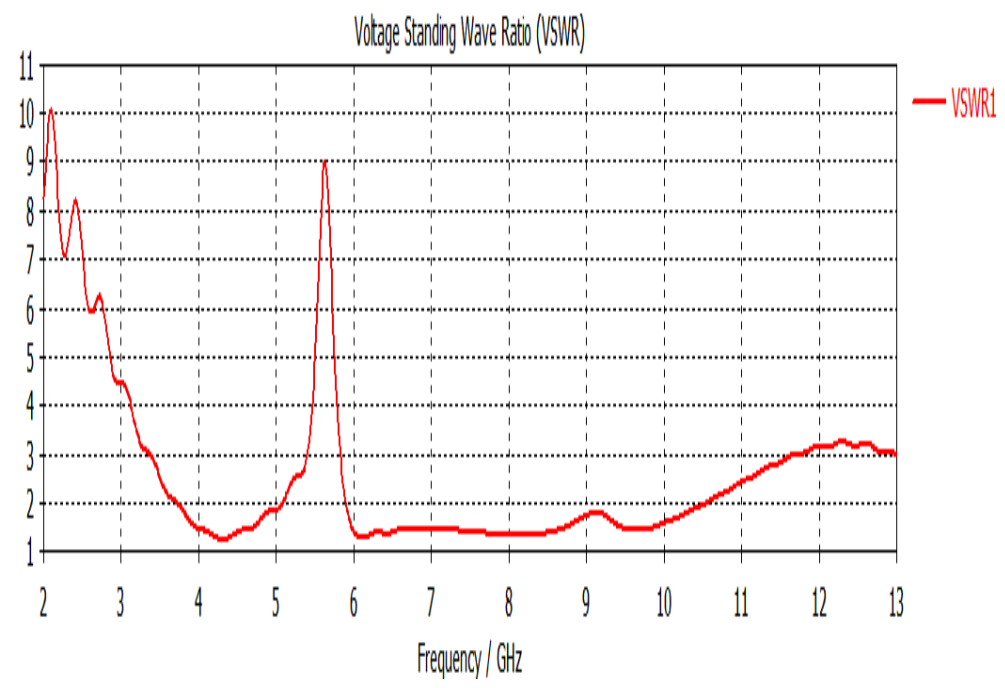

Figure 3. VSWR Plot of the Proposed UWB Antenna with Notching Characteristics 
The radiation pattern and gain plot of the proposed antenna is as shown in the Figure 4 and Figure 5

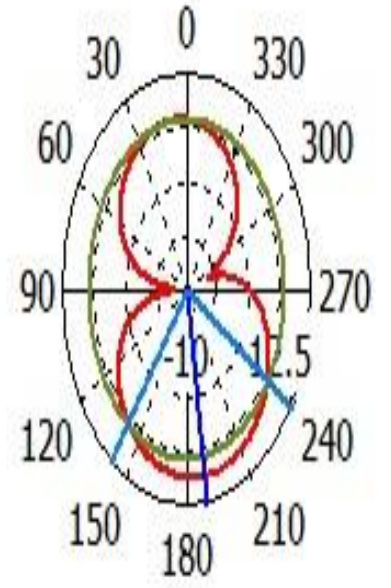

E-Plane

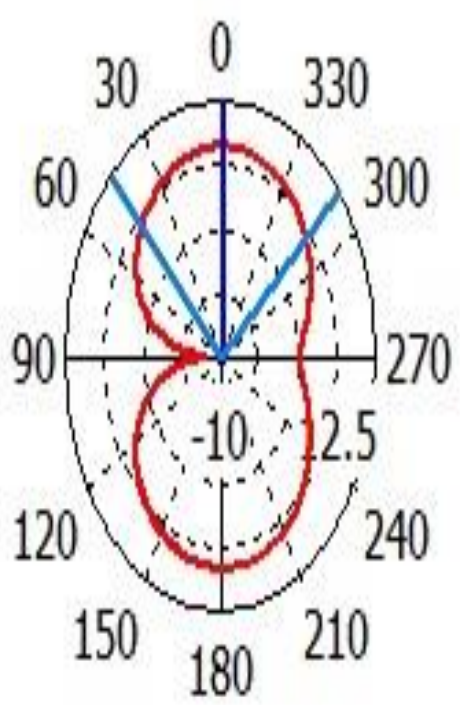

H-Plane

Figure 4. Radiation Pattern of the Proposed UWB Antenna at 4.3 GHZ

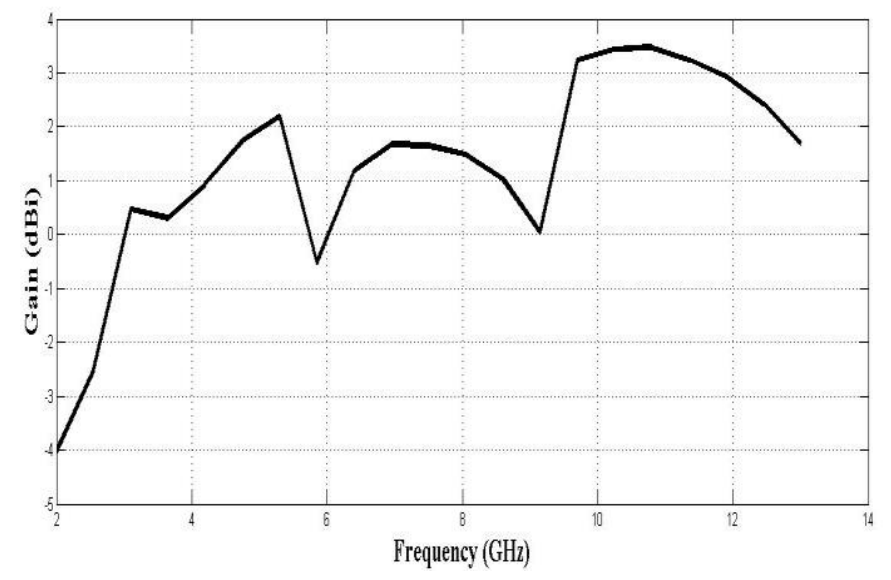

Figure 5. Gain Plot of the Proposed UWB Antenna

\section{Conclusion and Future Scope}

In this paper, UWB monopole antenna with band-notched characteristics is simulated and presented. By etching an inverted U-shaped slot in the radiating patch, the interference from WLAN band can be reduced. The antenna can be used for UWB applications since it has a bandwidth ranging from $3.7 \mathrm{GHz}$ to $10.4 \mathrm{GHz}$ with a stable radiation pattern and a band notch at $5.1 \mathrm{GHz}$ to $5.9 \mathrm{GHz}$. In future, this work can be extended by notching other bands presented in UWB in order to reduce the interference due to existing of several narrowband wireless standards. 


\section{Acknowledgments}

The author is thankful to Dr. K. JAGADEESH BABU, M. Tech., MIEEE, Ph. D, for his beneficial and professional help.

\section{References}

[1] FCC, "Ultra-Wideband Operation FCC Report and Order", Tech. Rep.US47 CFR, vol. 15, (2002).

[2] W. C. Liu and C. F. Hsu, "CPW-FED notched monopole antenna for UMTS/IMT 2000/WLAN applications", Journal of Electromagnetic Waves and Applications, vol. 21, no. 6, (2007), pp. 841-851.

[3] L. Xie, Y. C. Jiao, Y. Q. Wei and G. Zhao, "A compact band-notched UWB antenna optimized by a novel self-adaptive differential evolution algorithm", Journal of Electromagnetic Waves and Applications, vol. 24, nos. 17-18, (2010), pp. 2353-2361.

[4] A. A. L. Neyestanak, "Ultra wideband rose leaf microstrip patch antenna", Progress In Electromagnetics Research, vol. 86, (2008), pp. 155-168.

[5] H. Y. Xu, H. Zhang, K. Lu and X. F. Zeng, "A holly-leaf-shaped monopole antenna with low RCS for UWB application”, Progress In Electromagnetics Research, vol. 117, (2011), pp. 35-50.

[6] C. C. Lin, Y. C. Kan, L. C. Kuo and H. R. Chuang, "A planar triangular monopole antenna for UWB communication,'IEEE Microwave and Wireless Components Letters, vol. 15, no. 10, (2005), pp. 624626.

[7] Z. N. Chen, T. S. P. See and X. Qing, "Small printed ultra wideband antenna with reduced ground plane effect," IEEE Transactions on Antennas and Propagation, vol. 55, no. 2, pp. 383-388, (2007).

[8] N. Ojaroudi, M. Ojaroudi and Y. Ebazadeh, "UWB/Omni Directional Microstrip Monopole Antenna for Microwave Imaging Applications", (2014).

[9] C. R. Medeiros, J. R. Costa and C. A. Fernandes, "Compact tapered slot UWB antenna with WLAN band rejection", IEEE Antennas And Wireless Propagation Letters, vol. 8, (2009), pp. 661-664.

[10] A. M. Abbosh and M. E. Bialkowski, "Design of UWB planar bandnotched antenna using parasitic element", IEEE Trans, Antennas Propag, vol. 57, (2009), pp. 796-799.

\section{Authors}

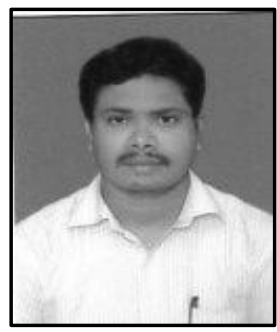

V.N. Koteswara Rao. Devana received his B.Tech. Degree in Electronics and Communication Engineering in 2004 from Acharya Nagarjuna University, Guntur, India and M.Tech. Degree in Systems \& Signal Processing from JNTU Hyderabad, India in 2011. Presently working Assistant prof. at SACET, JNTUK, Chirala. His research interests include Antennas and wave propagation, Wireless communications and Ultra Wideband Technology. As of today, he has published twelve (12) research papers in various journals and conferences.

N. Vyuha pursuing B.Tech degree in Electronics and

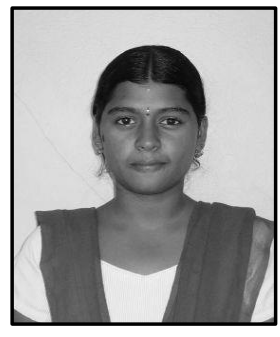
Communication Engineering from the JNTU University, Kakinada. Her areas of interest include Microstrip Antennas, UWB Antennas, and Wireless communications.

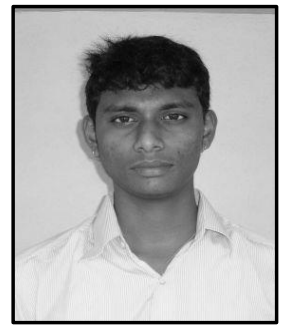

P. Nagasai pursuing B.Tech degree in Electronics and Communication Engineering from the JNTU University, Kakinada. His areas of interest include Microstrip Antennas, UWB Antennas, and Wirelesscommunications. 

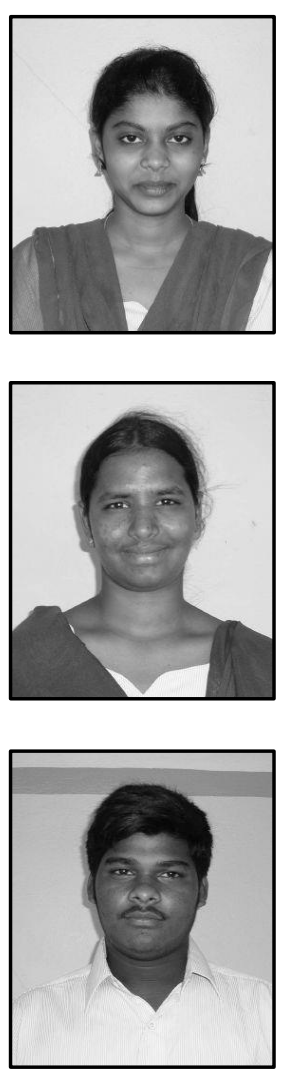

K. Sahitya pursuing B.Tech degree in Electronics and Communication Engineering from the JNTU University, Kakinada. Her areas of interest include Microstrip Antennas, UWB Antennas, andWirelesscommunications.

K. Divya pursuing B.Tech degree in Electronics and Communication Engineering from the JNTU University, Kakinada. Her areas of interest include Microstrip Antennas, UWB Antennas, and Wirelesscommunications.

K. Maheshwar Reddy pursuing B.Tech degree in Electronics and Communication Engineering from the JNTU University, Kakinada. His areas of interest include Microstrip Antennas, UWB Antennas and Wirelesscommunications. 